\title{
Analysis and Evaluation to a State's Fragility
}

\author{
Zirui Su, Yuting Nie, Fei Xie \\ Tianjin University, Tianjin, China \\ Email: 2438918201@qq.com
}

How to cite this paper: Su, Z.R., Nie, Y.T. and Xie, F. (2018) Analysis and Evaluation to a State's Fragility. International Journal of Modern Nonlinear Theory and Application, 7, 16-33.

https://doi.org/10.4236/ijmnta.2018.71002

Received: February 28, 2018

Accepted: March 23, 2018

Published: March 26, 2018

Copyright $\odot 2018$ by authors and Scientific Research Publishing Inc. This work is licensed under the Creative Commons Attribution International License (CC BY 4.0).

http://creativecommons.org/licenses/by/4.0/

(c) (i) Open Access

\begin{abstract}
Climate change is a global focus over the decades. It triggers many environment issues frequently, even serious natural disasters. The potential effects of the climate change are worse than itself. Many of these effects will gradually weaken the structure of society and government. As a result, the broken governments will turn into fragile states which refer to those states that are not able or choose not to provide the basic essentials to its people. We develop the fuzzy mathematics evaluation model to analyze the problem and evaluate the degree of a country's fragility, and we definite the fragility evaluation levels through the results in the model. In addition, we also apply our model to Yemen and compare the different situations whether considering climate change or not. Then we put our eyes on South Africa, a getting-warmer country in Africa. We construct the second model-Time series forecasting model, to grasp the changing fragility trend in South Africa and make prediction to see time and ways the fragility degree will change. Furthermore, we modify the forecasting model and use a brand new third model which is called grey model, to figure out the importance of Somalia governmental aid along with intervention by predicting that the arrival of drought in Somalia will be slowed down through positive response from the government.
\end{abstract}

\section{Keywords}

Fragility, Fuzzy Mathematics, Time Series Forecasting, Grey Forecast

\section{Introduction}

\subsection{Background}

The effects of climate change such as increased droughts, shrinking glaciers, changing animal and plant ranges and sea level rise will alter the way humans live today and may weaken or even break the structures of social and government, resulting in fragile states at last.

A fragile state which means the state government could not provide the basic 
essentials to its people. Some countries have become more fragile like Syria and Yemen due to the drought. Environmental stress alone may not trigger violent conflict, but it may enable violent conflict when it combines with weak fragmentation of government and society.

\subsection{Our Work}

- Construct a model to determine a country's fragility and measure the influence of climate change.

- Select a state from the top 10 most fragile states as determined by the Fragile State Index, then discuss how climate change increases fragility of that country. Use the constructed model to illustrate in what way(s) the state may be less fragile without these effects.

- Choose another state which is not included in the top 10 list to measure its fragility. Next observe the time and ways climate change push it into more fragile and define the tipping point for a country.

- Use the model to show which state driven interventions could reduce the risk of climate change and prevent a country from becoming a fragile state, and then give some suggestions or solutions.

- Determine whether the constructed model could work on other types of "states" such as cities or continents and modify the model.

\subsection{Literature Review}

After reading some documents about fragility in a country or a state, we have found that the most of them had sorted fragile countries and scored them from many aspects, according to the research paper by Mina Baliamoune-Lutz and Mark McGillivray in 2008, if the country policy and institutional assessment (CPIA) score falls below a particular threshold, the state will be classified as fragile, followed by illustrating how the situation is severe and appealing to us to prevent it. Besides, there have been some management to control the damage caused by climate change. We can see the optimistic solutions to manage the disaster and climate change damage in Geoff O'Brien, Phil O'Keefe, Joanne Rose and Ben Wisner's thesis-Climate change and disaster management. However, there are still some fields which are not covered clearly including prediction of a normal country to be a fragile country due to climate change, the costs of a certain state to restore the circumstance back to the former.

Our work aims to these unsolved problems and attempts to find some solutions to make them clear and feasible by using the mathematics and computer science models.

\section{Assumptions and Notations}

\subsection{Assumptions}

In order to quantify the issue responsibly and build mathematics models more scientifically, we think of that some assumptions must be taken into considera- 
tion:

- A certain country or a state could be simplified into specific elements and they will not affect mutually, so that fragility could be qualitative and quantitative.

- The elements are constant and will not change as time goes, to eliminate unnecessary effects.

- The contribution of each element to the fragility is equal without climate change.

- Every element weight will change only due to climate change because our research is aim to the relationship between climate change and fragility.

\subsection{Notations}

For clarifying the issue by using some effective solutions and visualize the problem through some formulas and models, we make the following notations to symbolize variables (See Table 1 ).

Table 1. Symbols \& meanings extracted from the "fragility" problem.

\begin{tabular}{|c|c|}
\hline Symbol & Meaning \\
\hline$u_{i}$ & Evaluation index \\
\hline$h_{i}$ & Evaluation level \\
\hline $\boldsymbol{R}$ & Fuzzy matrix \\
\hline $\boldsymbol{A}$ & Weight vector \\
\hline $\boldsymbol{F}$ & Ultimate weight vector \\
\hline$D$ & Judgement matrix \\
\hline$m_{i}$ & Factor in normalized $F$ \\
\hline$C_{p}$ & Cohesion point \\
\hline$E_{p}$ & Economy point \\
\hline$P_{p}$ & Politics point \\
\hline$S_{p}$ & Social point \\
\hline$U E$ & Ultimate Evaluation \\
\hline$g_{1}$ & Tipping point 1 \\
\hline$g_{2}$ & Tipping point 2 \\
\hline$\widehat{y_{t+1}}$ & The average of $y_{t} \sim y_{t-3}$ \\
\hline$y_{t}$ & The time series variable \\
\hline$S$ & The prediction standard deviation \\
\hline$a \%$ & The contribution rate of GDP \\
\hline$W$ & The Somalia's cost of intervention \\
\hline
\end{tabular}




\section{Determine the Conception of Fragility}

\subsection{Existing Conception}

The EU Council pointed out that vulnerability refers to structural weakness or failure, that is to say, the state is unable or unwilling to fulfill its basic functions, including the application of the rule of law, the protection of human rights and fundamental freedom and the protection of the general public [1].

\subsection{Qualitative}

According to the chapter 1.2 , we consider that it is necessary to clarify the definition of fragility first. In view of that a country or a sovereign state consists of economy, politics, population, social structure, therefore we conclude four aspects to definite fragility which are:

- Cohesion.

- Economy.

- Politics.

- Social.

It is universally acknowledged that these four factors are the fundamental parts to a certain state or a country, so once some of them change worse due to the climate change indirectly affect them, the fragility volume will increase and is mainly determined by the four factors above.

Then we divide fragility into following three levels to define the degree of fragility:

- Extreme Fragile.

- Vulnerable.

- Stable.

\subsection{Quantification and Standard}

To measure a certain state level of fragility, and next we construct models to qualify a country's fragility.

We evaluate fragility in the range of 0 to 10 , and determine the acceptable range for each element for simplifying and clarifying the degree of a country's fragility (See Table 2).

Table 2. The degrees of a country's fragility.

\begin{tabular}{|c|c|c|}
\hline \multicolumn{2}{|c|}{ Points } & Standard \\
\hline \multicolumn{2}{|c|}{$0-5$} & Stable \\
\hline \multicolumn{2}{|c|}{$5-8$} & Vulnerable \\
\hline \multicolumn{2}{|c|}{$8-10$} & Extreme Fragile \\
\hline Stable & Vulnerable & Extreme Fragile \\
\hline $0-5$ & $5-8$ & $8-10$ \\
\hline
\end{tabular}




\section{Model Design}

\subsection{Fuzzy Mathematics Evaluation Model}

\subsubsection{The Reason of Choosing the FME Model}

The FME Model always apply to quantify some fuzzy variables to construct a comprehensive evaluation. There are many applications about Fuzzy Mathematics Evaluation solutions in numbers of fields such as transportation, medical treatment, campus environment quality and so on. We focus on comparing the fragility to a state with campus environment quality and analyze some reports concerning Fuzzy comprehensive evaluation method of campus environment quality to find common points in the two subjects, then we decide to start with the theory to design our model.

\subsubsection{Evaluation Steps}

- 1) Determine evaluation factors set

$$
u=\left\{u_{1}, u_{2}, u_{3}, u_{4}\right\} .
$$

- 2) Determine evaluation levels set

$$
h=\left\{h_{1}, h_{2}, h_{3}, h_{4}\right\}
$$

- 3) Construct fuzzy relationship matrix $\boldsymbol{R}$

$$
\boldsymbol{R}=\left(\begin{array}{ccc}
r_{11} & \cdots & r_{1 n} \\
\vdots & \ddots & \vdots \\
r_{m 1} & \cdots & r_{m n}
\end{array}\right)
$$

The element $r_{m n}$ refers to fragility membership from the perspective of factor $u_{m}$ at $h_{n}$ level.

- 4) Determine the weight of each evaluation factor

$$
\begin{gathered}
\boldsymbol{A}=\left(a_{1}, a_{2}, a_{3}, \cdots, a_{q}\right), \sum_{i=1}^{q} a_{i}=1 \\
a_{q} \geq 0, i=1,2, \cdots, n
\end{gathered}
$$

We consider that it is necessary to introduce another model to figure out the weight vector A and we adopt the AHP model in chapter 4.2.

- 5) Integrate fuzzy synthesis evaluation result vector

After normalizing weight vector $A$ and figuring out the matrix $R$ we construct the ultimate weight vector $F$

$$
\boldsymbol{F}=\boldsymbol{A} \cdot \boldsymbol{R}=\left(a_{1}, a_{2}, a_{3}, \cdots, a_{q}\right)\left(\begin{array}{ccc}
r_{11} & \cdots & r_{1 n} \\
\vdots & \ddots & \vdots \\
r_{m 1} & \cdots & r_{m n}
\end{array}\right)
$$

\subsection{Sub Model}

The AHP Model

The AHP model helps us determine the relative importance between elements. AHP is a multiple criteria decision-making tool that has been used in almost all the applications related to the decision-making [2]. 
Construct Judgement Matrix

Matrix $D$

$$
\boldsymbol{D}=\left(D_{i j}\right)_{n \times n}, D_{i j}>0, D_{j i}=\frac{1}{D_{i j}}
$$

Then we use the criterion [3] for AHP.

After integrating our investigation and the change in rankings among a number of 178 states or countries over the years, we sort these four elements into the sheet (See Table 3): (The simulation will be shown in the part of Appendix).

So the judgement matrix is:

$$
\boldsymbol{D}=\left[\begin{array}{cccc}
1 & 1 / 2 & 1 / 4 & 1 / 5 \\
2 & 1 & 1 / 2 & 1 / 7 \\
4 & 2 & 1 & 1 / 3 \\
5 & 7 & 3 & 1
\end{array}\right]
$$

\subsection{The Solution of the Fuzzy Mathematics Model}

\subsubsection{Work out the Secondary Weight Vector}

We combine the result of AHP model and the fuzzy relationship matrix to obtain the secondary weight $\boldsymbol{F}=\boldsymbol{A} \cdot \boldsymbol{R}$ and then normalize it into normalized vector $\boldsymbol{F}^{\prime}$

$$
\boldsymbol{F}^{\prime}=\left(m_{1}, m_{2}, m_{3}, m_{4}\right)
$$

\subsubsection{Synthesis}

After constructing the vector $\boldsymbol{F}^{\prime}$, we make use of the statistics from FSI [4] and improve them in order to match them with vector $\boldsymbol{F}^{\prime}$ through synthesis evaluation score method, followed by judging and classifying the scores according to the standard in Chapter 3.2.

$$
\text { Ultimate Evaluation }(U E)=m_{1} * C_{p}+m_{2} * E_{p}+m_{3} * P_{p}+m_{4} * S_{p}
$$

\section{Model Application}

\subsection{Simulation for a Top 10 Country}

\subsubsection{Yemen, the Typical Country in the Top 10 List}

From the Fragile State Index, We show great interest in Yemen, because it is going through a deadlock about conflict at present-Yemen civil war [5]. The situation in Yemen is turbulent: Houthi \& pro-Saleh forces and Hadi government

Table 3. The evaluation of four elements' mutual effects.

\begin{tabular}{ccccc}
\hline Factors \& Relativity & Cohesion & Economy & Politics & Social \\
\hline Cohesion & 1 & $1 / 2$ & $1 / 4$ & $1 / 5$ \\
Economy & 2 & 1 & $1 / 2$ & $1 / 7$ \\
Politics & 4 & 2 & 1 & $1 / 3$ \\
Social & 5 & 7 & 3 & 1 \\
\hline
\end{tabular}


are struggling with each other (Figure 1). It will help us to apply our FME model to a typical country which is fragile and bearing the party split.

We concern the cause why the conflict happened to Yemen, and negative effects the war brings to the country rather than the struggle itself.

\subsubsection{The Effect Climate Change Brings to Yemen}

1) Climate condition

Temperatures are hot in the day, but fall dramatically at night. Perennial streams occur in the highlands, but these never reach the sea because of high evaporation in the Tihamah. The central highlands are an extensive high plateau over $2000 \mathrm{~m}$ (6562 ft) in elevation. This area is driver than the western highlands because of rain-shadow influences, but still receives sufficient rain in wet years for extensive cropping. Water storage allows for irrigation and the growing of wheat and barley. Yemen's portion of the Rub al Khali desert in the east is much lower, generally below $1000 \mathrm{~m}$ (3281 ft), and receives almost no rain [7].

2) Losses and GDP growth damage

\section{- Losses}

We can see that the liquefaction takes the lead in mortality (Figure 2) and the flood domains in economic losses from Nationally reported losses from 1990 to 2014 (Figure 3).

\section{- GDP growth damage}

The country has been thwarted from 1992 to 2016 which is also can be seen from the GDP growth (annual\%) [9], and the two obvious sharp drops are vividly shown from the changing curve (Figure 4 ):

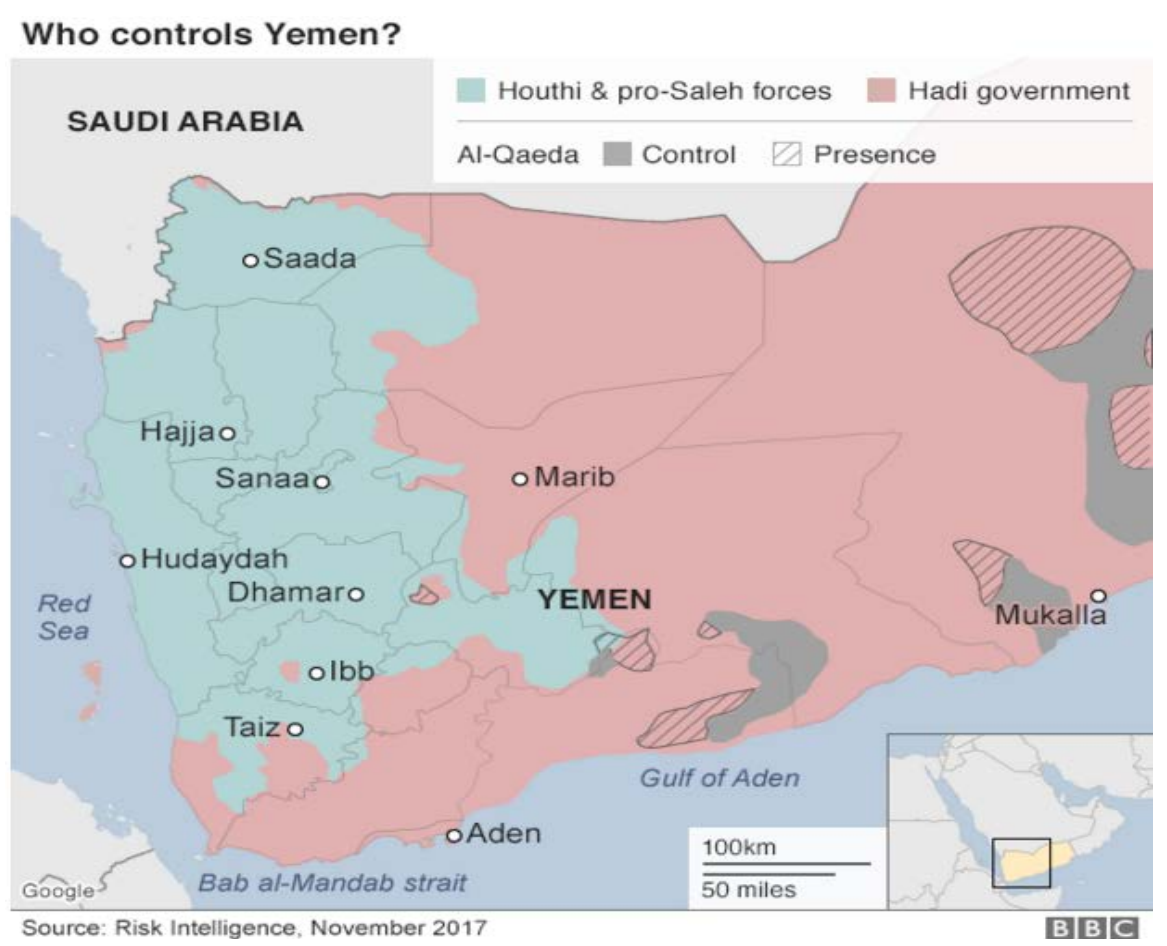

Figure 1. Who controls Yemen [6]? 


\section{Mortality}

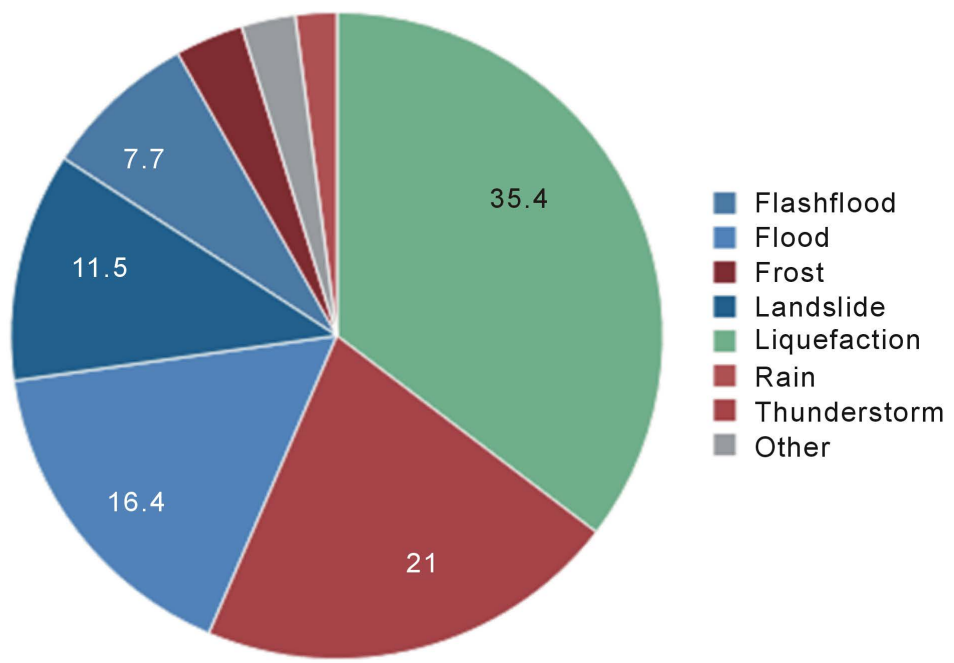

Figure 2. Mortality.

\section{Combined economic losses}

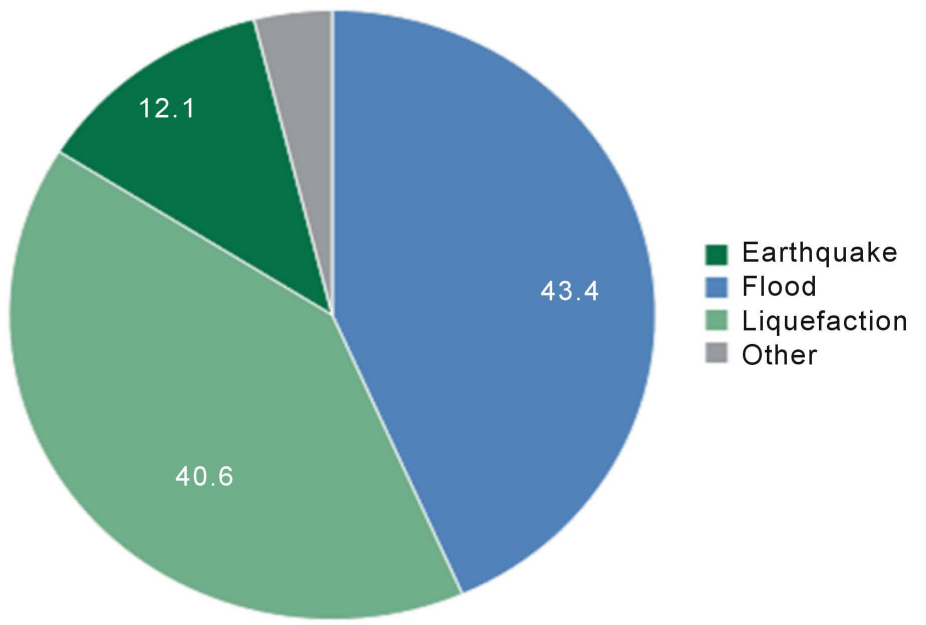

Figure 3. Nationally Reported Losses 1990-2014 [8].

\subsubsection{Comparison}

We apply the FME model to Yemen, comparing climate change and non-climate change curves from 2007 to 2017. It is clearly that the red curve (climate change curve) is higher than the blue curve (non-climate change) most of the time (Figure 5), so we conclude that the climate change effect on fragility cannot be ignored.

\subsection{Simulation for a State Not in the Top 10 List}

\subsubsection{Focus on the Climate in South Africa}

We pay attention to South Africa (ranks $96^{\text {th }}$ and scores 72.3 points from Fragile State Index). We look up to documents and news from social media, finding out that the most disturbing problems of climate change are: 


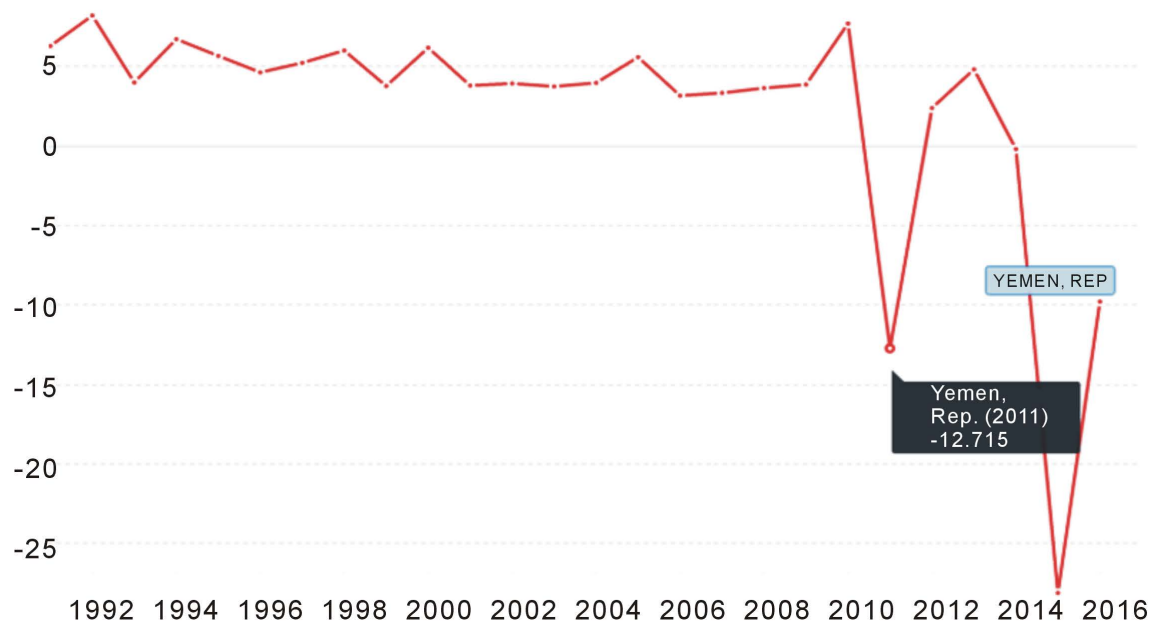

Figure 4. Two sharp drops in the diagram.

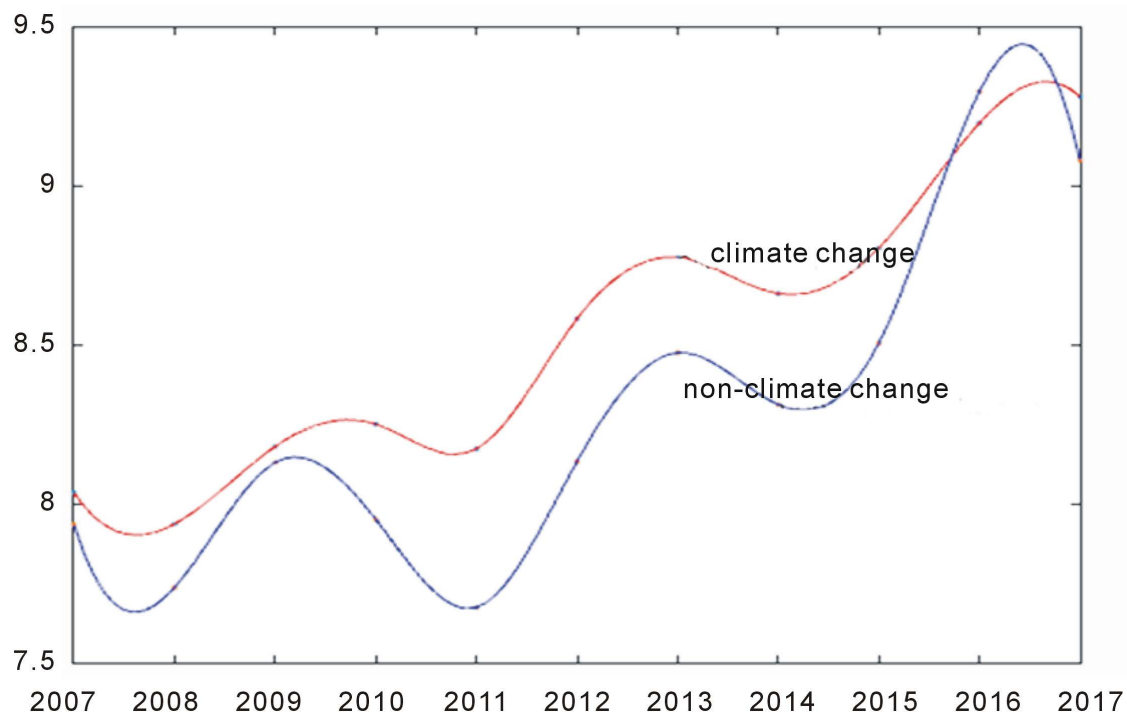

Figure 5. Compare the red curve with the blue curve.

- Growing carbon dioxide emission.

- Serious natural disasters.

\subsubsection{Global Warming to South Africa}

Global warming trend is sweeping across the world, especially in Africa illustrated from the Fragile States Index heat map (Figure 6). South Africa is suffering a lot, and it is at WARNING level from the standard which is set by The Fund for Peace in 2017:

\subsubsection{Destructive Natural Disasters}

- Earthquakes:

The worst earthquake to hit South Africa was in Tulbagh, an area located in the Winelands area of the Western Cape, on the 29th of September 1969, it measured a staggering 6.5 on the Richter Scale, the most recent powerful earthquake 


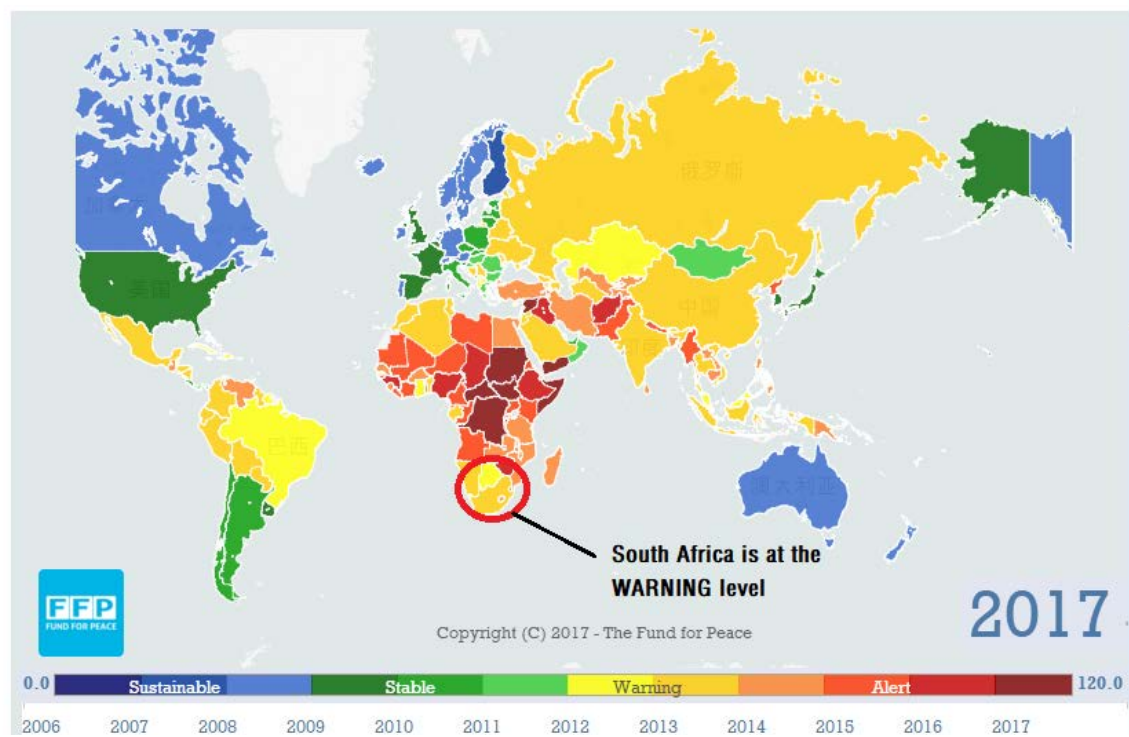

Figure 6. The heat map [10] displays South Africa is a "warm" country in 2017.

in Orkney only measured 5.5. The Tulbagh earthquake remains the most destructive in South African History. The earliest reported earthquake took place on Robben Island in 1620 however the accuracy of the account has been questioned.

- Floods:

On the $25^{\text {th }}$ of January 1981, the town of Laingsburg was devastated by a severe flood which left over a hundred people dead, 72 of the victim's bodies were never recovered. 184 houses were destroyed and only 21 houses remained standing in the town. The town was hit by a flash flood after very heavy rains (425mm over two days) which caused the nearby Buffalo River to burst its banks which resulted in the entire town being covered in the deluge [11].

\subsection{Definite the Tipping Point}

- We consider that once a certain state of fragility shifts to another state, to be specific, a country's state change from "vulnerable" to "stable", it must go through the tipping point.

- We update our former standard in chapter 3.3 (Table 2), in order to definite the tipping or turning point. The fragility is still evaluated from $0-10$ which is generally clarified in the sheet (See in Table 4):

Identification:

- When a country's $U E$ shifts from range $\left[0, g_{1}\right]$ to $\left[g_{1}, g_{2}\right]$, it is identified as passing the tipping point $g_{1}$;

- When a country's $U E$ shifts from range $\left[g_{1}, g_{2}\right]$ to $\left[g_{2}, 10\right]$, it is identified as passing the tipping point $g_{2}$;

- When a country's $U E$ shifts more than one range, it is identified as passing the two points. 
Table 4. Tipping points $g_{1}, g_{2}$ in evaluation.

\begin{tabular}{cc}
\hline Points & Standard \\
\hline $0-g_{1}$ & Stable \\
$g_{1}-g_{2}$ & Vulnerable \\
$g_{2}-10$ & Extreme Fragile \\
\hline
\end{tabular}

\subsubsection{Prediction Model}

According to the diagram with respect to South Africa on Fragile State Index [12] (Figure 7), South Africa is always ranking the one of the lowest countries but the situation is worse and worse over the years from 2006 to 2017.

Our team consider that it is necessary to give solutions to predict when and how the country becomes more fragile under the influence of climate change, still focus on these evaluation factors and find out whether the country's standard will shift passing the tipping point, either. To predict scientifically, we use the Time Series Forecasting Model to work out the issue.

\subsubsection{Description of the Model}

Time Series Forecasting Model is aim to forecast the time of the target and study the changing trend, besides, a time series is often a combination of several forms.

\subsubsection{Prediction Formula and Standard Deviation}

$$
\begin{gathered}
\widehat{y_{t}}=\frac{y_{t}+y_{t-1}+y_{t-2}+y_{t-3}}{N}, t=N, \cdots, 12 \\
S=\sqrt{\frac{\sum_{t=N}^{12}\left(\hat{y}_{t}-y_{t}\right)^{2}}{12-N}}
\end{gathered}
$$

We use the two formulas to predict the fragility shift in South Africa with its $U E$ factor from 2006 to 2017 we have calculated, to find out the years and ways to South Africa changing its fragility standard. We do loop computing successively to solve out the statistics from 2018 (Vulnerable) to a certain year (EXtreme Fragile) in the future (The result will be shown in the part of Appendix).

\subsubsection{Further Research in South Africa}

The country faces immense social problems-poverty and inequality, unemployment, HIV/AIDS and personal and property insecurity-which have barely improved since the apartheid era, or even deteriorated. Ten million people-23 per cent of the population-were living on less than $\$ 2$ per day in 2000 , and an estimated 37 per cent were below a nationally defined poverty line [13].

\subsection{Intervention Mechanism}

\subsubsection{Somalia's Response}

Somalia government has been taken actions (Figure 8) to prevent and deal with the drought issue [14]. 


\begin{tabular}{|c|c|c|c|c|c|c|c|c|c|c|c|c|c|c|}
\hline \multirow[b]{2}{*}{2017} & \multirow{2}{*}{$\begin{array}{l}\text { Rank } \\
\text { 96th }\end{array}$} & \multicolumn{13}{|c|}{ 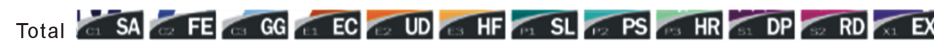 } \\
\hline & & 72.3 & 6.1 & 6.1 & 6.7 & 7.1 & 7.5 & 5.5 & 6.5 & 7.0 & 4.2 & 7.2 & 5.4 & 3.0 \\
\hline 2016 & 108th & 69.9 & 5. & \multirow{5}{*}{\multicolumn{5}{|c|}{$\begin{array}{c}\text { South Africa } \\
\text { Year: 2017 } \\
\text { Overall Rank: 96th of } 178 \\
\text { countries } \\
\text { C1: Security Apparatus: } 6.1\end{array}$}} & 5.0 & 7.2 & 4.4 & 7.3 & 5.6 & 3.2 \\
\hline 2015 & 113th & 67.0 & 5. & & & & & & 5.3 & 6.4 & 4.3 & 7.0 & 5.9 & 3.1 \\
\hline 2014 & 115th & 66.6 & 4. & & & & & & 5.0 & 6.1 & 4.3 & 7.4 & 6.2 & 3.2 \\
\hline 2013 & 113th & 67.6 & 5. & & & & & & 5.3 & 6.3 & 4.2 & 7.8 & 6.5 & 2.9 \\
\hline 2012 & 115th & 66.8 & 4. & & & & & & 5.2 & 5.8 & 4.5 & 8.1 & 6.4 & 2.8 \\
\hline 2011 & 116th & 67.6 & 4.5 & 5.9 & 5.9 & 5.3 & 8.2 & 4.1 & 5.5 & 5.5 & 4.6 & 8.4 & 6.7 & 3.0 \\
\hline 2010 & 115th & 67.9 & 4.1 & 5.9 & 5.6 & 5.0 & 8.5 & 4.4 & 5.8 & 5.5 & 4.7 & 8.4 & 7.0 & 3.0 \\
\hline 2009 & 122th & 67.4 & 4.3 & 5.9 & 5.3 & 4.6 & 8.5 & 4.3 & 5.5 & 5.7 & 4.5 & 8.4 & 7.4 & 3.0 \\
\hline 2008 & 125 th & 62.7 & 3.9 & 4.4 & 4.9 & 4.2 & 8.5 & 4.0 & 5.0 & 5.7 & 4.2 & 8.4 & 7.0 & 2.5 \\
\hline 2007 & 132th & 57.4 & 3.2 & 3.9 & 4.7 & 2.8 & 8.5 & 4.0 & 4.3 & 5.7 & 4.1 & 8.2 & 6.0 & 2.0 \\
\hline 2006 & 110th & 55.7 & 3.4 & 4.0 & 4.5 & 2.2 & 8.0 & 4.0 & 4.1 & 6.0 & 4.0 & 7.7 & 5.8 & 2.0 \\
\hline
\end{tabular}

Figure 7. The statistics table from 2006 to 2017.

The ICRC in Somalia is helping communities access whatever water is available, and so far this year has assisted 760,000 people.

\subsubsection{Grey Model and Cost}

\section{1) Grey Model}

Given a row of origin statistic $\left(x^{(0)}(1), x^{(0)}(2), \cdots, x^{(0)}(n)\right)$, to constant $\zeta$, if $x^{(0)}(i)>\zeta$, we identify it as abnormal number(s). Next we pick them from the row and form another row of statistic, the new row of statistic is the disaster sequence.

We construct $G M(1,1)$ model which means that it contains only level 1 and 1 variable-the rainfall statistics from 2006 to 2017 with the accumulate method to predict how Somalia will be less fragile in the future.

After we predict the year of the drought in Somalia next time, we emphasize that it is vital to realize the importance of the aid for the Somalia government, as its response for drought in 2017 and should intensify the investigation.

\section{2) Cost Prediction}

To Somalia, we classify water and sanitation activities with relief activities into the standard Economy and Social, and then we put health care activities in Politics and Cohesion.

Before the Somalia's intervention, we use the vector

$$
S 01=\left(C_{p}, E_{p}, P_{p}, S_{p}\right)
$$

After the Somalia's intervention, the vector changes into

$$
S 02=\left(C_{p}^{\prime}, E_{p}^{\prime}, P_{p}^{\prime}, S_{p}^{\prime}\right)
$$

Define

$$
S 01_{(1)}=C_{p}
$$

Then we follow the rule

$$
S 01_{(2)}=E_{p}
$$



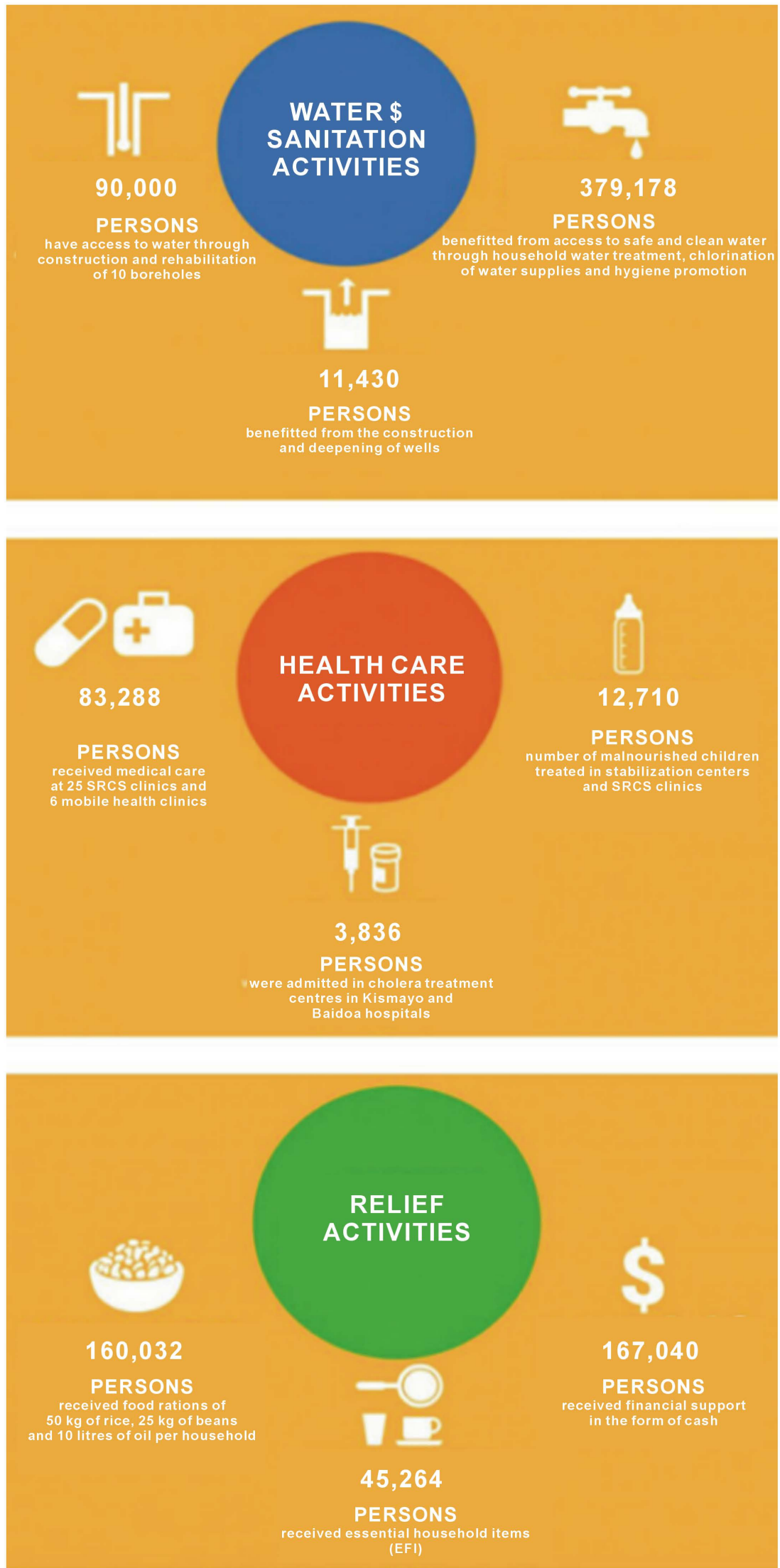

Figure 8. ICRC's aid. 
In view of a country's $G D P$ contribution rate to every factor is different, we introduce the rate $a \%$ to determine the share of the two main category. Now we can infer the cost formula:

$$
\begin{aligned}
W= & G D P * a \% *\left(\frac{S 01_{(1)}-S 02_{(1)}}{S 01_{(1)}}+\frac{S 01_{(4)}-S 02_{(4)}}{S 02_{(4)}}\right) \\
& +G D P *(1-a \%) *\left[\frac{S 01_{(2)}-S 02_{(2)}}{S 01_{(2)}}+\frac{S 01_{(3)}-S 02_{(3)}}{S 01_{(3)}}\right]
\end{aligned}
$$

\section{Modification}

\section{The bigger or smaller one?}

More recently, cities have emerged as a new category of fragility in the security and development landscape. With unprecedentedly fast urbanization rates, cities are becoming the focal point of global poverty, conflict, and vulnerability to disasters-particularly when situated within a fragile state [15].

\section{Conclusions}

\section{- Strengths}

We improve our algorithm in AHP model, and integrate $R$ with AHP model to build the complete Fuzzy Mathematics Model. We opportunely apply our prediction models to successfully predict the situation in Yemen and Somalia. Through our work, we consider that the FME model and prediction models are necessary to accurately evaluate the degree of a state's fragility and helpful for the government to take actions to reduce the damage caused by the climate change.

\section{- Weaknesses}

There are also some cons along with the pros during our modeling process.

The determination of $R$ may be subjective, and the Time Series Forecasting model is strongly dependent on the statistics from our investigation, so the deviation cannot be neglected. Our assumptions may be a little incomplete or somewhat needless, and the notations may have mutual effects, in order to simplify the problem we ignore them.

\section{- Future work}

First, we will improve our models to avoid using the data which is not convincing enough or somewhat subjective. Secondly, we are devoted to finding some more rational algorithms and analyzing the issue in a multi-dimensional way such as the relationship between the extent of climate change and national aid cost over the years.

Besides, we also show great interest in fragility in Asian countries like China, Korea, Japan and so on.

\section{References}

[1] European Council (2007) Council Conclusions on an EU Response to Situations of 
Fragility. 19-20 November.

[2] Analytic Hierarchy Process: An Overview of Applications, Omkarprasad S. Vaidya, Sushil Kumar, 2006.

[3] https://en.wikipedia.org/wiki/Analytic_hierarchy_process_\%E2\%80\%93_leader_exa $\underline{\text { mple }}$

[4] Fragile State Index. http://fundforpeace.org/fsi/

[5] https://en.wikipedia.org/wiki/Yemeni_Civil_War_(2015\%E2\%80\%93present

[6] Yemen Crisis: Who Is Fighting Whom? BBC News, World-Middle East, 2018. http://www.bbc.com/news/world-middle-east-29319423

[7] https://en.wikipedia.org/wiki/Yemen\#Regions_and_climate

[8] https://www.preventionweb.net/countries/yem/data/

[9] https://data.worldbank.org/indicator/NY.GDP.MKTP.KD.ZG?locations=YE

[10] http://fundforpeace.org/fsi/

[11] https://briefly.co.za/4773-video-shows-uzalo-stars-beauty-netizens-throw-shade.ht $\mathrm{ml} \# 4773$

[12] Fragile State Index. http://fundforpeace.org/fsi/

[13] LSE Research Online, Jo Beall, Stephen Gelb and Shireen Hassim, Fragile Stability: State and Society in Democratic South Africa.

[14] Somalia Drought Emergency Response in 2017. https://www.icrc.org/en/document/somalia-drought-emergency-response-2017

[15] Discussion Paper Fragile States and Fragile Cities, Independent Commission on Multilateralism. 


\section{Appendix}

- AHP Model

Table A1. The fundamental scale for pairwise comparisons.

\begin{tabular}{|c|c|c|}
\hline \multicolumn{3}{|c|}{ The Fundamental Scale for Pairwise Comparisons } \\
\hline $\begin{array}{l}\text { Intensity of } \\
\text { Importance }\end{array}$ & Definition & Explanation \\
\hline 1 & Equal importance & $\begin{array}{l}\text { Two elements contribute equally to the } \\
\text { objective }\end{array}$ \\
\hline 3 & Moderate importance & $\begin{array}{l}\text { Experience and judgment moderately favor } \\
\text { one element over another }\end{array}$ \\
\hline 5 & Strong importance & $\begin{array}{l}\text { Experience and judgement strongly favor one } \\
\text { element over another }\end{array}$ \\
\hline 7 & Very strong importance & $\begin{array}{l}\text { One element is favored very strongly over } \\
\text { another, its dominance is demonstrated in } \\
\text { practice }\end{array}$ \\
\hline 9 & Extreme importance & $\begin{array}{l}\text { The evidence favoring one element over } \\
\text { another is of the highest possible order of } \\
\text { affirmation }\end{array}$ \\
\hline
\end{tabular}

Intensities of $2,4,6$, and 8 can be used to express intermediate values. Intensities of $1.1,1.2,1.3$, etc. can be used for elements that are very close in importance.

$\mathrm{B} 1=\left[\begin{array}{lllll}1 & 1 / 2 & 1 / 4 & 1 / 5 & ; \\ 2 & 1 & 1 / 2 & 1 / 7 \\ 4 & 2 & 1 & 1 / 3 & ; \\ 5 & 7 & 3 & 1\end{array}\right] ;$

$[\mathrm{n}, \mathrm{n}]=\operatorname{size}(\mathrm{B} 1)$;

$[\mathrm{v}, \mathrm{d}]=\operatorname{eig}(\mathrm{B} 1)$;

$\mathrm{r}=\mathrm{d}(1,1)$;

$\mathrm{CI}=(\mathrm{r}-\mathrm{n}) /(\mathrm{n}-1)$;

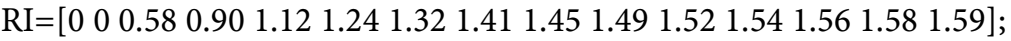

$\mathrm{CR}=\mathrm{CI} / \mathrm{RI}(\mathrm{n})$;

if $\mathrm{CR}<0.1$

CR_Result='Pass';

else

CR_Result='Failed';

end

$\mathrm{w}=\mathrm{v}(:, 1) / \operatorname{sum}(\mathrm{v}(:, 1))$;

$\mathrm{w}=\mathrm{w}^{\prime}$;

disp('Please judge the matrix weight vector calculation report: ');

disp('CI:');

$\operatorname{disp}($ num2str(CI));

$\operatorname{disp}(' \mathrm{CR}:)$;

$\operatorname{disp}($ num2str(CR));

disp('CR Result:'); 
disp(num2str(CR_Result));

disp('Eigenvalue:');

$\operatorname{disp}($ num2str(r));

disp('weight vector:');

$\operatorname{disp}(\operatorname{num} 2 \mathrm{str}(\mathrm{w}))$;

Inconsistent degree

Consistent Index

$$
C I=\frac{\lambda-n}{n-1}
$$

Consistent rate

$$
C R=\frac{C I}{R I},
$$

When $C R<0.1$, the consistency check result is Pass.

- Vector A:

$$
\boldsymbol{A}=\left[\begin{array}{llll}
0.073746 & 0.11084 & 0.22847 & 0.58695
\end{array}\right]
$$

- Matrix R:

$$
\boldsymbol{R}=\left[\begin{array}{llll}
0.058 & 0.277 & 0.556 & 0.110 \\
0.160 & 0.489 & 0.310 & 0.041 \\
0.040 & 0.328 & 0.466 & 0.167 \\
0.041 & 0.225 & 0.499 & 0.236
\end{array}\right]
$$

- Time Series Forecasting Predict Model Statistics

Table A2. Time series forecasting predict model statistics

\begin{tabular}{lll}
\hline 2006 & 4.7615 \\
2007 & 4.9071 \\
2008 & 5.2982 \\
2009 & 5.5896 \\
2010 & 5.6606 \\
2011 & 5.5631 \\
2012 & 5.5155 \\
2013 & 5.5961 \\
2014 & 5.4963 \\
2015 & 5.5895 \\
2016 & 5.7992 \\
2017 & 6.0201 \\
2018 & 5.9871 \\
2019 & 6.1098 \\
2020 & 6.2399 \\
2021 & 6.3500 \\
\hline & \\
\hline & & \\
\hline
\end{tabular}




\section{Continued}

\begin{tabular}{|c|c|}
\hline 2022 & 6.4325 \\
\hline 2023 & 6.5439 \\
\hline 2024 & 6.6524 \\
\hline 2025 & 6.7555 \\
\hline 2026 & 6.7894 \\
\hline 2027 & 6.8992 \\
\hline 2028 & 7.0159 \\
\hline 2029 & 7.1339 \\
\hline 2030 & 7.2285 \\
\hline 2031 & 7.3383 \\
\hline 2032 & 7.4480 \\
\hline 2033 & 7.5561 \\
\hline 2034 & 7.6616 \\
\hline 2035 & 7.7699 \\
\hline 2036 & 7.8778 \\
\hline 2037 & 7.9583 \\
\hline 2038 & 8.0925 \\
\hline
\end{tabular}

South Africa will be 'Extreme Fragile' in 2038.

- Grey Model code

$\mathrm{a}=[220.8,224.9,246.8,262.8,276.0,214.8,356.1,225.7,250.9,259.1,238.7,275.2$, 269.1,285.7,263.8,281.2,287.7,263.4,254.5,244.6,292.6,258.1,302.3,259.8] ;

$\mathrm{t} 0=$ find $(\mathrm{a}<=250)$;

$\mathrm{t} 1=$ cumsum $(\mathrm{t} 0)$;

$\mathrm{n}=$ length(t1);

$\mathrm{B}=\left[-0.5^{*}(\mathrm{t} 1(1\right.$ :end -1$)+\mathrm{t} 1(2$ :end $))$, ones $\left.(\mathrm{n}-1,1)\right] ; \mathrm{Y}=\mathrm{t} 0(2$ :end $)$;

$\mathrm{r}=\mathrm{B} \backslash \mathrm{Y}$

$\mathrm{y}=\mathrm{d}$ solve $\left(' \mathrm{Dy}+\mathrm{a}^{\star} \mathrm{y}=\mathrm{b}^{\prime}, \mathrm{y}(0)=\mathrm{y} 0^{\prime}\right)$;

$\mathrm{y}=\operatorname{subs}\left(\mathrm{y},\left\{\mathrm{a}^{\prime}, \mathrm{b}^{\prime}, \mathrm{y0} 0^{\prime}\right\},\{\mathrm{r}(1), \mathrm{r}(2), \mathrm{t} 1(1)\}\right)$;

yuce $1=\operatorname{subs}\left(y, t^{\prime},[0: n+1]\right)$

digits(6)

$\mathrm{y}=\mathrm{vpa}(\mathrm{y})$

yuce $=$ diff $($ yuce 1$)$

yuce $=[\mathrm{t} 0(1)$, yuce $]$ 